2-20-2015

\title{
Research Framework, Strategies, And Applications Of Intelligent Agent Technologies (IATs) In Marketing
}

V. Kumar

Georgia State University, vk@gsu.edu

Ashutosh Dixit

Cleveland State University, a.dixit1@csuohio.edu

Rajshekar G. Javalgi

Cleveland State University, r.javalgi@csuohio.edu

Mayukh Dass

TexasTech University, mayukh.dass@ttu.edu

Follow this and additional works at: https://engagedscholarship.csuohio.edu/bus_facpub

Part of the Marketing Commons

How does access to this work benefit you? Let us know!

Publisher's Statement

The final publication is available at Springer via http://dx.doi.org/10.1007/s11747-015-0426-9

\section{Original Published Citation}

Kumar, V., Dixit, A., Javalgi, R.G., Dass, M. (2016). Research framework, strategies, and applications of intelligent agent technologies (IATs) in marketing. Journal of the Academy of Marketing Science, 44(1), 24-45. doi:10.1007/s11747-015-0426-9

This Article is brought to you for free and open access by the Monte Ahuja College of Business at EngagedScholarship@CSU. It has been accepted for inclusion in Business Faculty Publications by an authorized administrator of EngagedScholarship@CSU. For more information, please contact library.es@csuohio.edu. 


\title{
Research framework, strategies, and applications of intelligent agent technologies (IATs) in marketing
}

\author{
V. Kumar • Ashutosh Dixit • Rajshekar (Raj) G. Javalgi • \\ Mayukh Dass
}

\begin{abstract}
In this digital era, marketing theory and practice are being transformed by increasing complexity due to information availability, higher reach and interactions, and faster speeds of transactions. These have led to the adoption of intelligent agent technologies (IATs) by many companies. As IATs are relatively new and technologically complex, several definitions are evolving, and the theory in this area is not yet fully developed. There is a need to provide structure and guidance to marketers to further this emerging stream of research. As a first step, this paper proposes a marketing-centric definition and a systematic taxonomy and framework. The authors, using a grounded theory approach, conduct an extensive literature review and a qualitative study in which interviews with managers from 50 companies in 22 industries reveal the importance of understanding IAT applications and adopting them. Further, the authors propose an integrated conceptual framework with several propositions regarding IAT adoption. This research identifies the gaps in the literature and the need for adoption of IATs in the future of marketing given changing consumer behavior and product and industry characteristics.
\end{abstract}

\author{
V. Kumar $(\bowtie)$ \\ J. Mack Robinson College of Business, Georgia State University, \\ Atlanta, GA 30302, USA \\ e-mail: vk@gsu.edu \\ A. Dixit $\cdot$ R. G. Javalgi \\ Ahuja College of Business, Cleveland State University, \\ Cleveland, OH 44115, USA \\ A. Dixit \\ e-mail: a.dixit1@csuohio.edu \\ R. G. Javalgi \\ e-mail: r.javalgi@csuohio.edu \\ M. Dass \\ Rawls College of Business, Texas Tech University, \\ Lubbock, TX 79409, USA \\ e-mail: mayukh.dass@ttu.edu
}

Keywords Intelligent agent technologies · Marketing strategy $\cdot$ Grounded theory

The growth of online marketing and increasingly tough competitive realities have led to a paradigm shift in marketing, where understanding needs and demands of each individual customer is becoming increasingly important, and it has become critical for companies to respond to market dynamics accurately and quickly. The revenue for the intelligent technology-based predictive analytics market is expected to grow by $22 \%$ each year to $\$ 5.25 \mathrm{~B}$ by 2018 (August 2013, www.marketsandmarkets.com). ${ }^{1}$ Companies such as Amazon, eBay, and Netflix are embracing intelligent agent technologies (henceforth referred to as IATs, or "Agents") for collaborative filtering, personalization, recommendation systems, and price-comparison engines to facilitate exchanges in the marketplace (Iacobucci et al. 2000).

Recent literature (e.g., Bodapati 2008; Chen and Sudhir 2004; Clemons 2009; Diehl et al. 2003; Iyer and Pazgal 2003) has taken important initial steps and discussed complex marketing applications of IATs that were developed in different contexts and time-frames. For example, Iyer and Pazgal 2003 show how IATs affect market competition in general. Similarly, Chen and Sudhir 2004 and Diehl et al. 2003 examine how IATs such as shopbots and smart agents affect price competition and sensitivity in e-commerce settings. Bodapati 2008 shows how sensitivity of intelligent recommendation systems affects consumer behavior. In their recent empirical paper focusing on the banking industry, Köhler et al. 2011 find

\footnotetext{
${ }^{1}$ See http://www.marketsandmarkets.com/Market-Reports/predictiveanalytics-market-1181.html.
} 
that interaction style and content of online agents do influence customer adjustment to new and complex service contexts, and in turn impact account performance. Other papers, such as Clemons 2009, have explored the policy issues surrounding use of IATs.

There is, however, confusion in terms of what IATs mean for markets and marketers; when, where, and how these innovations can be adopted; and what implications they have for marketing theory and practice (Köhler et al. 2011). One reason for such a gap is the lack of in-depth understanding and synthesis of research in marketing as IATs are highly complex and sophisticated technologies and research about their applications is evolving. This has led to multiplicity of labels, several overlapping descriptions of marketing applications, and incomplete and limited taxonomies. Moreover, many of the innovative applications are not presented clearly and adequately in the literature (e.g., market governance, competitive intelligence), nor have their underlying principles (e.g., autonomy, decision making) been discussed cohesively. Thus, there is an imperative need for a marketing conceptualization of IATs and a related unifying taxonomy of marketing applications linking underlying principles and circumstances under which each can be adopted.

The aim of this paper is to provide a comprehensive understanding of IATs and their applications to marketing. We focus on the following three main research questions that deal with conceptual/theoretical understanding, applications, and IATs' outcomes/performance, respectively:

1. What are the recent developments in the field of marketing that are related to IATs, and how can they be classified based on marketing concepts?

2. What are the opportunities and challenges associated with the adoption of IATs in the marketing domain, and how to conceptually link them together?

3. How do the marketing applications of IATs enhance firm performance?

To address these research questions, we focus on the following objectives. First, we develop a conceptual marketingcentric definition of IAT and provide relevant examples of marketing applications of IATs (that go beyond simple price comparison smart agents) (Diehl et al. 2003). We propose a unifying taxonomy of IATs based on the underlying marketing concepts and IAT characteristics that (a) is logical, relevant, and useful for researchers and managers and (b) demonstrates the relationships and differences among IATs' marketing applications. In line with the second and third research questions, our second objective is to develop a managerially focused framework and propositions that are needed for IAT adoption considerations. Our study makes an important contribution to the field of marketing in terms of theory development and application pertaining to IATs.
Based on a thorough review of literature and using a grounded theory approach, we first develop a marketing definition of IATs and a marketing taxonomy. We then integrate relevant factors that influence adoption of IATs by companies to propose a research framework and propositions. Finally, conclusions and an agenda for further research are presented.

\section{Understanding intelligent agent technologies: theoretical perspectives and review of literature}

The extant marketing literature on IATs seems to be fragmented, with researchers focusing on individual aspects. While theoretical foundations are in development, there seems to be a need for integration of IAT characteristics and underlying marketing concepts.

At a fundamental level, IATs have the ability to overcome traditional marketing boundaries, to support adaptive marketing by continuously revising and updating new product information and price offerings in real-time and satisfy customer demands (Rust and Oliver 1994; Rust and Varki 1996). This potential has encouraged researchers to teach consumer concepts to IATs. For instance, the Open Mind project at MIT has collected over 700,000 facts from over 14,000 participants to teach concepts to create sentient computers. Another IAT example is GloBuddy2, which learns contextually relevant information by extracting key concepts from phrases submitted by users (Liberman et al. 2004). In a similar way, research on marketing applications of IATs is growing and gaining attention among marketing scholars (Bodapati 2008; Chen and Sudhir 2004; Clemons 2009; Diehl et al. 2003; Iyer and Pazgal 2003; Köhler et al 2011; Maes 1994; Smith 2002; Timmers and Gasós 2001). Marketing scholars have also begun to consider the policy aspects and guidelines of IATs with respect to the use of information (e.g., misdirection, privacy concerns).

In these contexts, research on agent characteristics (e.g., autonomy, mobility, and intelligence and their relationships to marketing concepts) is of prime importance (Shardanand and Maes 1995). Consider the concept of autonomy. To function effectively, an intelligent agent must learn its owner's preferences but also guard against the dynamic nature of strategies that extract information and intrude on privacy information. Thus, it is important to understand and build revelation (i.e., revealing pertinent information) principles into IATs that will aid in developing such secured characteristics (Bace 2000).

In its current stage, the marketing literature falls somewhat short in providing an in-depth exposition of IATs that will help marketing academics and practitioners expand on and adopt IATs more effectively. Moreover, the extant literature (Köhler et al. 2011) suggests that more theoretical and applied research is needed to explore marketing applications of IATs. 
Therefore, in this paper, we set out to address the above gap in the literature. A brief review of marketing literature on IATs is presented in Table 1.

As noted in Table 1, there are several conceptualizations that are present in the marketing literature. For example, studies on IATs have focused on their automation aspects (Bodapati 2008), their ability to dynamically scan market environments (Chen and Sudhir 2004; Diehl et al. 2003), their learning capacities about competitors (Iyer and Pazgal 2003), and how they contribute toward expanding the concepts of customer value and the importance of customer-centricity for facilitating exchange and enhancing firm value (Kumar and Reinartz 2012). Moreover, these automated systems are also capable of interpreting information; analyzing, learning, and drawing inferences to solve marketing issues such as understanding consumer preference (Chen et al. 2008); and negotiating with sellers (Huang et al. 2010).

According to Wooldridge 2002, IATs are intelligent software or computer systems that are autonomous and possess important properties such as learning, social ability, reactivity, and pro-activeness to perform a set of complex tasks. These concepts, while covering important aspects of IATs, are not easily comprehensible to traditional marketing academics and practitioners. Our conceptualization integrates and expands these concepts to increase their comprehension and assimilation. We contribute to the literature by expanding our understanding of IATs, and provide insights by comparing and contrasting IATs to traditional marketing actors/entities, e.g., human agents, and also traditional computer programs.

First, IATs can be similar to human agents in handling complex information and business rules (e.g., travel agents, real estate agents); however, they are different from human agents in the sense that IATs inhabit online environments and can assimilate a vast amount of information, carry out tasks with greater speed, efficiency, and accuracy.

Second, we clarify that IATs are designed in such a way that they possess intelligence (artificial) and have the potential to solve complex problems effectively, thus differentiating them from ordinary computer programs. For example, one could see how a typical payroll program is not an intelligent agent, as its current output is not related to past analysis or environmental factors, but based on certain preset rules. Thus, a payroll program fails the test of temporal continuity and cannot be proactive in a changing environment (see Franklin and Graesser 1996).

Third, we explain that IATs are not hardwired like traditional software or expert systems to perform specific tasks, but they possess intelligence based on logic and learning that enables them to learn user preferences or negotiating strategies. For example, Maxims, a mail filtering agent, could learn user preferences by examining user decisions over time, and correspondingly make internal predictions based on logic of what the user will do with the email. Based on this logic and learning over time it can start making suggestions to the user of possible courses of action regarding email (Maes 1994).

Fourth, we add to the understanding of IATs by conceptualizing them as dynamic systems. Based on the situation, they may be either proactive or reactive, and they can counter the strategies or tactics of others in a dynamic environment. For example, based on the notion of virtual or machine-tomachine collaboration with common languages or semantics, IATs can form coalitions to obtain discounts through virtual group buying situations.

Finally, we emphasize that IATs have learning abilities. IATs have the capability to gain insights into individual customer needs and wants and to increase market efficiency by searching information databases and matching market offerings to customer needs. Such capabilities of IATs make them a potential game changer in the future of marketing with longterm impact on marketing theory and practice (Köhler et al. 2011).

Based on the above, we present a marketing-centric definition of IATs as:

\section{Intelligent agent technologies (IATs) are computational systems that inhabit a complex dynamic environment and continuously perform marketing functions such as (a) dynamic scanning of the environment and market factors including competitors and customers, and firm actions impacting the marketing mix; (b) collaborating and interacting to interpret perceptions, analyzing, learning and drawing inferences to solve problems; and (c) implementing customer-focused strategies that create value for the customers and the firm within the boundaries of trustworthiness and policy.}

\section{Qualitative study}

Research strategy

The goal of the qualitative study was to develop a marketing-centric definition and a taxonomy and framework for IAT adoption. Qualitative studies have been found to be especially useful in researching new phenomenon and concepts (Sinkovics et al. 2005). In this study, selected managers from a diverse group of companies were our primary informants. Each manager was asked to describe and discuss the use of IATs in their firm. We iteratively identified and refined our IAT taxonomy and antecedents and consequences of IAT adoption with the help of the initial interviews, which provided a theoretical focus for subsequent interviews. We also delved into related literature throughout the process to develop the theoretical framework for our research. 


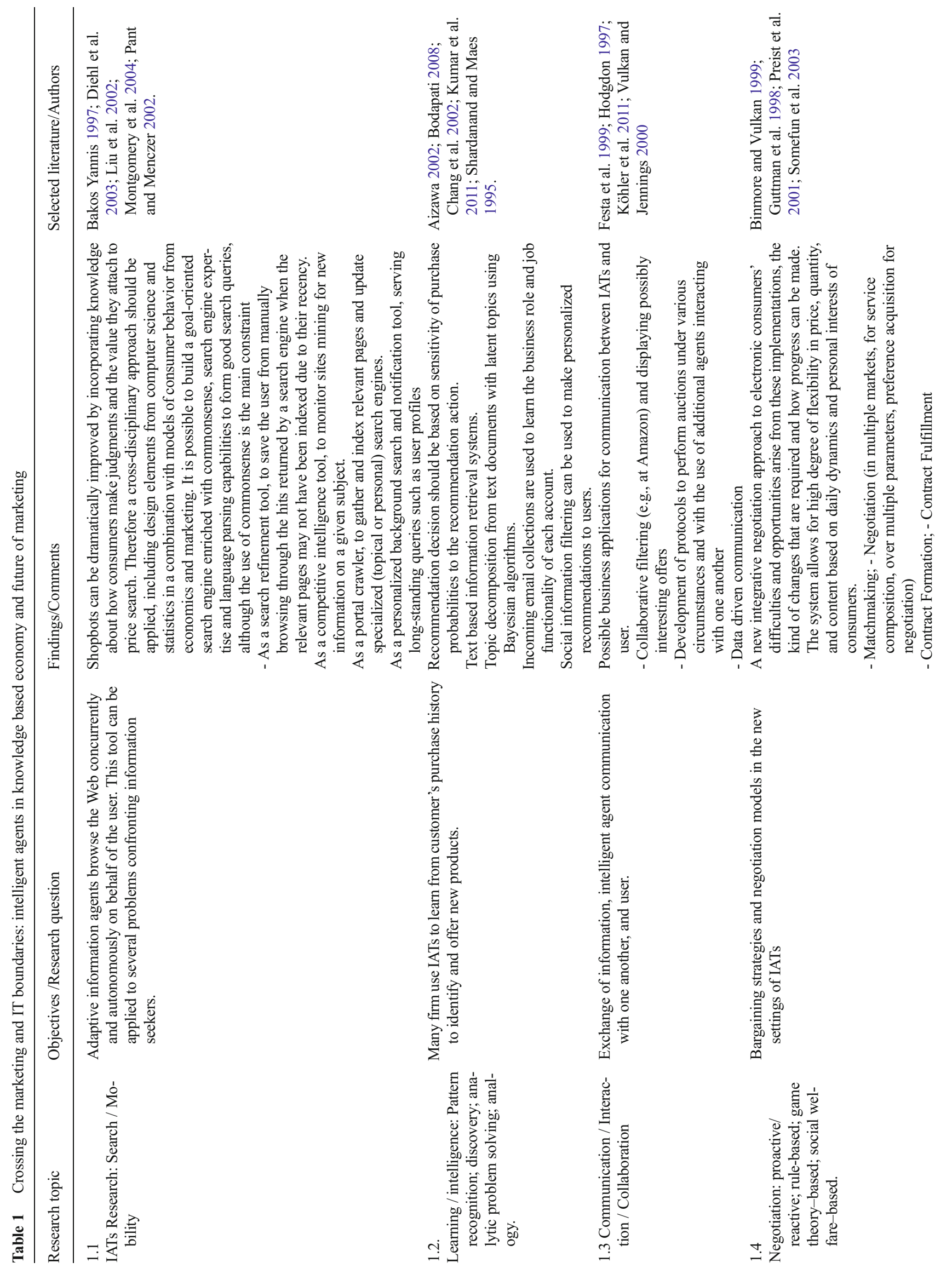


Sample

In order to discover the collective interpretations of IATs, we sought viewpoints from a sample of 100 managers from 50 companies (randomly selected from a list of 1,000 companies) in 22 industries about the adoption and utilization of IATs. Of these 50 companies, 27 were business-to-business companies and 23 were business-to-consumer companies. From each firm, we made sure that we had at least two responses - one from the marketing manager and one from the IT manager. We were able to complete 100 interviews representing these 50 companies in a period of four weeks. Our data were collected through in-depth interviews on an exploratory questionnaire developed based on an extensive review of literature. Interviews with industry experts were conducted as they were considered to be closest to the research area and have high knowledge and expertise in this area due to hands-on experience. The interviews were then analyzed by two independent researchers and the findings used to generate the taxonomy and the conceptual framework. We follow the work of Glaser and Strauss 1967 and Glaser 1998 for grounded theory development.

Analysis

We used a grounded theory approach (Strauss and Corbin 1998; Beverland et al. 2010) to analyze the interview data. Grounded theory is based on the premise that the researcher can obtain data from respondents with experience in a certain area where the theory is not fully developed and the topic at hand is relatively new (Goulding 2002). This helps the researcher to obtain deeper understanding of the phenomenon to add to the extant literature. The grounded theory method provides a detailed understanding of the issues related to the subject of inquiry. Furthermore, the grounded theory method supplements the existing concepts and theories in the case of newer areas where these are not fully developed. As per Glaser (1994), the grounded theory generation depends on:

1. A discovery-based approach including researchers' own ideas based on literature review, knowledge from general articles regarding IATs, and interviews with industry experts.

2. Consideration of a wide range of ideas available depending on the state of knowledge in the field. Therefore, a broad range of ideas were chosen. These ideas were in various categories, properties, characteristics, and innovations as they relate to IATs and their marketing applications.

3. Applying these findings, linkages, and comparisons to generate theory. These ideas were developed and were applicable to several parts of the taxonomy and the framework. 
We first identified the reasons why firms adopt IATs and the challenges they face while doing so. During this process, we examined for similarities and differences among the concepts. Next, we related categories and sub-categories to one another, which resulted in the initial framework of the IAT taxonomy. This was followed by examining the literature to determine theoretical linkages among the components of the taxonomy. Finally, we integrated the evolved concepts to propose a taxonomy and framework.

To maintain consistency in data collection in terms of probing, style, and depth of inquiry into the subject matter, the lead author conducted all of the interviews. The interview questions were related to the awareness of IAT applications and competitive advantages of IATs. Specifically, the questions pertained to: (a) the adoption of IATs, (b) the drivers of utilization of IATs, or the conditions in which companies are more likely to adopt IATs, (c) the role of IAT adoption in achieving a sustainable competitive advantage (SCA), and (d) the possibility of industry equilibrium when the competition also adopts IATs.

Some sample responses were:

"In our business, market factors affect the way we adopt IATs to stay competitive."

"In our organization IAT features (such as information search, acquisition) impact the use of IATs."

"Our managers constantly reconfigure resources to adapt to the changing environment."

"To stay competitive, our organization leverages technological capabilities."

"In our company IAT plays a critical role in creating value to our customers and firm."

"Our organization emphasizes customization and digitization of products..."

Most marketing managers emphasized the importance of understanding the benefits of adopting IATs. Their major concerns were whether the adoption of IATs would (a) provide them a competitive advantage, (b) generate higher revenue and profit, (c) cause the firm to be perceived as an innovative firm, and (d) result in a better firm evaluation by the Wall Street. On the other hand, most IT managers mainly focused on the applications of IATs. These IT managers generally were concerned with (a) the integration of IATs into the marketing function, (b) the cost-benefit trade-offs, and (c) whether their firm is a viable candidate for adoption of IATs.

Our qualitative analysis indicates that antecedents (e.g., customer characteristics, product characteristics, firm resources and capabilities, and industry/market dynamics) are likely to influence adoption of IATs, and the SCA is likely to be higher for the early adopters. Early adopters can potentially acquire insights into customer needs and respond before competitors, which can lead to increased market share, carry-over effects, and higher business performance (Kumar et al. 2011). Furthermore, environmental drivers such as technological, economic, and regulatory factors are likely to moderate the effects of IAT adoption and utilization on firm performance. In rapidly changing markets, efficient acquisition, dissemination, and usage of information may translate into higher customer acquisition, satisfaction, and retention, leading to higher market share and profitability. We collated the findings from the above qualitative study along with the related literature to develop a marketing-centric taxonomy of IATs.

\section{A marketing taxonomy of IATs}

Using the grounded theory approach above, we focus on developing a comprehensive marketing taxonomy of IATs. Taxonomical frameworks, whether explicit or implicit, include a thorough investigation of the discipline's phenomena and general guidelines for pursuing such investigations (Tellis 1986; Hunt 2002; Olson et al. 2005). The tremendous scientific importance of taxonomies is well recognized in the literature. Social sciences have made heavy use of taxonomies, providing a detailed picture of relatedness and differences. While taxonomies are different than theories, they are no less important, and building taxonomies is no less daunting than developing theories. While theories attempt to clarify the implications that are inherent in concepts, taxonomies help to identify and explain patterns that exist in nature. Both physical and social sciences have made heavy use of taxonomies.

As IATs are relatively new, marketing applications appear only in a piecemeal fashion. Our proposed taxonomy systematically breaks down the wide array and confusing nomenclature associated with IATs into easily recognizable groups from a marketing perspective. We believe that our proposed taxonomy is of high scientific importance as it will contribute to the marketing literature by guiding researchers to explore complex innovations and build theoretical foundations to advance the field.

\section{Classification scheme}

We propose a marketing taxonomy of IAT (Fig. 1) by integrating the IAT characteristics and marketing concepts/objectives of the firms obtained from our qualitative study discussed earlier. In particular, we focus on the five internal characteristics of IATs: (1) search, (2) learning, (3) negotiation, (4) decision making, and (5) collaboration; and the four marketing objectives: (1) market governance, (2) customer orientation (optimizing marketing mix, customer heterogeneity), (3) competitor orientation (maximizing competitive opportunities), and (4) learning orientation. This yields a total of $5 \times 4$ or twenty-cell taxonomy, with each cell having a potential to 
Fig. 1 A marketing taxonomy of IATs

\begin{tabular}{|c|c|c|c|c|}
\hline \multirow[b]{2}{*}{$\begin{array}{c}\text { Agent } \\
\text { Characteristics }\end{array}$} & \multicolumn{4}{|c|}{ Marketing Objectives/Concepts } \\
\hline & $\begin{array}{c}\text { Market } \\
\text { Governance }\end{array}$ & $\begin{array}{c}\text { Customer } \\
\text { Orientation }\end{array}$ & $\begin{array}{l}\text { Competitor } \\
\text { Orientation }\end{array}$ & $\begin{array}{c}\text { Learning } \\
\text { Orientation }\end{array}$ \\
\hline $\begin{array}{l}\text { Information } \\
\text { Search \& } \\
\text { Acquisition }\end{array}$ & $\begin{array}{l}\text { Market Information } \\
\text { Agents: Public } \\
\text { information of every } \\
\text { agent e.g., GRAPPA }\end{array}$ & $\begin{array}{l}\text { Customer } \\
\text { Intelligence Agents: } \\
\text { e.g., Prospect Miner, } \\
\text { Customer profiling } \\
\text { Webwatcher, } \\
\text { NewsDude. }\end{array}$ & $\begin{array}{l}\text { Competitor } \\
\text { Intelligence } \\
\text { Agents: e.g., Active } \\
\text { Business. }\end{array}$ & $\begin{array}{l}\text { Learning Search } \\
\text { Agents: Price search, } \\
\text { product search, } \\
\text { merchant search e.g., } \\
\text { Fido, Bargain-finder, } \\
\text { Firefly. }\end{array}$ \\
\hline $\begin{array}{c}\text { Information } \\
\text { Analysis: Pattern } \\
\text { recognition, } \\
\text { discovery, } \\
\text { analytic problem } \\
\text { solving, analogy }\end{array}$ & $\begin{array}{l}\text { Market Analysis } \\
\text { Agents: Market } \\
\text { analysis, } \\
\text { Matchmaking e.g., } \\
\text { LARKS (Language } \\
\text { for Advertisement } \\
\text { and Requests for } \\
\text { Knowledge Sharing) }\end{array}$ & $\begin{array}{l}\text { Customer } \\
\text { Information Analysis } \\
\text { Agents : Buyer } \\
\text { preference, } \\
\text { acquisition, } \\
\text { collaborative } \\
\text { filtering, e.g., } \\
\text { ADEPT, Letizia, } \\
\text { Personal searcher. }\end{array}$ & \begin{tabular}{l|} 
Competitor \\
Analysis Agents: \\
e.g., memory-based \\
reasoning in real \\
time, e.g., Kora, \\
NetBase, \\
Deepblue.
\end{tabular} & $\begin{array}{l}\text { Learning Analysis } \\
\text { Agents: Product } \\
\text { brokering, e.g., } \\
\text { Addall }\end{array}$ \\
\hline $\begin{array}{l}\text { Interaction and } \\
\text { Negotiation: } \\
\text { proactive/reactive, } \\
\text { rule-based, game } \\
\text { theory-based, } \\
\text { social welfare- } \\
\text { based. }\end{array}$ & $\begin{array}{l}\text { Market Negotiation } \\
\text { Agents: Brokering } \\
\text { Facilitator/ } \\
\text { negotiation } \\
\text { mechanisms, results } \\
\text { of past negotiations } \\
\text { e.g., Scottrade } \\
\text { brokerage agent }\end{array}$ & $\begin{array}{l}\text { Customer } \\
\text { Negotiation Agents: } \\
\text { Relating customer } \\
\text { history, preferences, } \\
\text { willingness, and } \\
\text { ability to pay, e.g. } \\
\text { Priceline automated } \\
\text { agents }\end{array}$ & $\begin{array}{l}\text { Competitor } \\
\text { Response Agents: } \\
\text { Understanding and } \\
\text { proactively pre- } \\
\text { empting or } \\
\text { responding to } \\
\text { competitor } \\
\text { strategies and } \\
\text { tactics in real time, } \\
\text { e.g. Lending Tree, } \\
\text { Deepblue. }\end{array}$ & $\begin{array}{l}\text { Learning } \\
\text { Negotiation Agents: } \\
\text { Chanel relations and } \\
\text { negotiations, Price } \\
\text { negotiations, bidding } \\
\text { strategies, e.g. } \\
\text { Bazaar, Inspire, } \\
\text { Smartsettle, } \\
\text { Deepmind. }\end{array}$ \\
\hline $\begin{array}{r}\text { Auto } \\
\text { Decisior }\end{array}$ & $\begin{array}{l}\text { Market } \\
\text { Authentication } \\
\text { Agents: availability } \\
\text { Matchmaking e.g., } \\
\text { LARKS }\end{array}$ & $\begin{array}{l}\text { Recommendation } \\
\text { Agents: Accelerated } \\
\text { real time offers in } \\
\text { milliseconds based } \\
\text { on customer } \\
\text { information e.g., } \\
\text { Lycos, Pragmatic } \\
\text { Chaos }\end{array}$ & \begin{tabular}{l|} 
Competitive \\
Decision Making \\
Agents: Real time \\
price comparisons, \\
and pricing tactics \\
evaluation and \\
response. e.g. \\
pricewatch
\end{tabular} & $\begin{array}{l}\text { Learning Decision } \\
\text { Agents: Price } \\
\text { setting, } \\
\text { recommendation } \\
\text { agents, } \\
\text { customization, } \\
\text { personalization, } \\
\text { advertising. e.g. } \\
\text { truecar }\end{array}$ \\
\hline $\begin{array}{c}\text { Collaborative (All } \\
\text { characteristics of } \\
\text { individual agents } \\
\text { above plus) }\end{array}$ & $\begin{array}{l}\text { Multi-agent systems: } \\
\text { BDI systems. Trust } \\
\text { mechanisms, public } \\
\text { information of every } \\
\text { agent. e.g. LIDS }\end{array}$ & $\begin{array}{l}\text { Coalition Agents: } \\
\text { formation for group } \\
\text { buying and } \\
\text { negotiations, } \\
\text { Privacy, } \\
\text { confidentiality, } \\
\text { authentication, } \\
\text { availability } \\
\text { Systems. e.g. CATS, } \\
\text { Jasmere }\end{array}$ & $\begin{array}{l}\text { Competitive } \\
\text { Collaborative } \\
\text { Agents: Threats, } \\
\text { masquerade, trust, } \\
\text { BDI systems. e.g. } \\
\text { LIDS, NED }\end{array}$ & $\begin{array}{l}\text { Learning } \\
\text { Collaboration } \\
\text { Agents: Vickery } \\
\text { auctions, English } \\
\text { auctions Anonymity, } \\
\text { traceability, traffic } \\
\text { analysis, liability. } \\
\text { e.g., Saffronart }\end{array}$ \\
\hline
\end{tabular}

result in an IAT application. We also provide a sixth row depicting social and policy implications for each IAT role. However, in practice, many of these occur jointly and may be complex to interpret.

The applications of IATs often cross over the boundaries of this framework. However, we hope that it will help the readers to understand and organize the literature. The Agent Characteristics column in Fig. 1 provides a description of IAT characteristics based on computer sciences literature, where intelligent agents have searching, learning, negotiating, decision making, and collaboration capabilities. This column provides aspects of IATs that could be mapped onto the market orientation construct of market sensing or information search, information analysis, and learning, negotiations, and decisionmaking or implementation, respectively (Kohli and Jaworski 1990). The heading row in Fig. 1 is derived from marketing concepts/objectives such as market governance, customer orientation, competitor orientation, and learning orientation.

\section{Agent characteristics}

IATs possess internal characteristics such as autonomy, intelligence, interactivity, and mobility that facilitate information exchange at much higher efficiency than humanly possible, leading to an increase in company market orientation (Köhler et al. 2011). Agent technologies can influence the intangible aspects of marketing, such as trust building, customer retention, and loyalty, as well as the tangible aspects, such as market share and return on investment (ROI). The adoption of IATs, when coupled with smart marketing concepts and protocols, allows companies to function innovatively, while at the same time safeguarding their self-interests and group interests, which ultimately leads to competitive advantage. For example, IATs participating in a virtual marketplace and negotiating with other agents/humans is an innovation that can lead to competitive advantage. 
Using our classification scheme, we divide IAT applications broadly into (1) information search, acquisition, and analysis and (2) interaction through communication, collaboration, and negotiation. Now, we present a description and examples of programs/agents for each of the IAT characteristics and the related market-oriented applications.

Information search Agents not only enhance consumer search and reduce search costs but also provide vital information to companies about their customers and competitors (Bodapati 2008; Iacobucci et al. 2000). The vast amount and dynamic nature of the information on the Web makes it challenging for humans to find and monitor relevant and recent information (Pant and Menczer 2002). IATs have the capability to collect and mine real time product and price information from thousands of websites. They can also learn user preferences in terms of price and quantity, and provide better fit and marketing efficiencies due to an expansive reach and faster access to information. For example, adaptive IATs called "spiders" act as intelligent clients on behalf of the user, searching the Web to retrieve information.

Information acquisition Agents provide opportunities to track consumers who visit a firm's website by gathering detailed information about their demographics, psychographics, and purchase behavior. Companies may also use IATs to track and maintain information about consumers' personalization and make customized offers (Murthi and Sarkar 2003). For example, Double Click uses cookies to profile customers' click-through rates and time spent on the Internet. This information, combined with other sources (e.g., scanner databases, census data), enables the company to create customer profiles and offer personalization. Personalization allows website managers to alter their content according to the interests, preferences, and buying habits of a consumer (Shardanand and Maes 1995). This personalization is accomplished with (1) customization or manual filtering of content by the consumer, (2) predefined business rules and/or constraints, or (3) collaborative filtering.

Information analysis Agents can find non-obvious, statistical relationships among items by investigating how often two or more items appear in the same context, or interact with a consumer during the same browsing or shopping session. As traditional retail stores often use market basket analysis to consider the items people purchase during the same visit, and then rearrange their stocking methods, IATs can rearrange virtual malls and products on e-commerce websites by analyzing consumers' preferences, deduced by recording visitors' transactions. An agent can also conduct competitor and market structure analysis online. Websites of competitors and Internet retail stores offer valuable resources for the dynamic capture and analysis of competitor information, which can provide a deeper understanding of competitors' business, strengths, weaknesses, and future strategic and tactical moves. For example, (Sheng et al. 2005) note that software agents programmed to generate tracking numbers can retrieve delivery information for competitors' products, and then use that information to identify competitors' geographical markets and major accounts.

Online communication, interaction and negotiations Existing research focuses on the abilities of IATs to enhance interaction and communication (Hoffmann and Novak 1996), collaboration, and negotiations (Iyer and Pazgal 2003; Köhler et al. 2011). IATs support data-driven communication and could be of immense value in marketing communications, specifically in heterophilous groups, where communication and exchange of information otherwise would be limited. They can also act as bridges among different heterophilous networks, turning them into larger networks, leading to wider and faster diffusion of knowledge. Internet and mobile devices are making communication ubiquitous, which supports prior findings.

Autonomy in decision making Decision making in competitive environments is an important role of human marketing managers. Autonomy is perhaps the one of the most difficult concepts for marketing applications of IATs. Autonomy is sometimes understood in the literature as an equivalent of liberty, or independence in the case of decision making. The freedom and self-direction of IATs are bounded by moral and ethical values that legitimize their decision making. In many cases the autonomy of IATs may be restricted more tightly as compared to humans due to the need for adherence to preconceived explicit notions.

The autonomy in decision making exercised at different functional levels of the firm by IATs may have different rationales and different objectives. Furthermore, there may be external influences that may unexpectedly change and impact decisions. These external changes, while similar to both the principal and IATs, may evoke remarkably different responses and/or decisions based on history, discrepancies in information and usage of heuristics in certain instances. Other complexities may arise due to the nature of the objectives themselves. Therefore, IATs' decision making is tempered by the evaluation of managers' beliefs about the future.

The autonomy of IATs in decision making implies rules of reason that are bounded by moral and ethical considerations. The boundaries of these may not be clear and applications in different contexts may be difficult, and paths of action may conflict with each other due to various inherent conflicts in various ethical theories.

Further, the autonomy of IAT in decision making can provide assistance and guidance to their human counterparts in forming and testing coalitions, strategies, interactions and negotiations. In this sense, IATs exercise autonomy from 
traditional belief systems and assumptions, and provide alternative and novel perspectives for decision-making.

Collaboration and integration Agents are classified into three systems: (1) individual (work specifically for the user), (2) collaborative (communities that cooperate to achieve a goal), or (3) societal (developed to operate in complex, dynamic environments) (Timmers and Gasós 2001). According to (Chaib-Draa and Dignum 2002, p. 89), "an important part of agent approach is the principle that agents (like humans) can function more effectively in groups that are characterized by cooperation and division of labor." A collaborative or societal system of IATs could integrate into marketing at various levels. IATs not only drive the key processes that need to be integrated but could also align marketing functions to company systems and objectives. They can synchronize and update information across different management and marketing functions as well as across companies. Similarly, collaborative IATs may also provide transparency across customer relationships and sales initiatives. Reward systems could be integrated in the process. Furthermore, collaborative IATs can gather and synthesize information for proactive marketing and a future orientation. This information can also be used to design future strategies and elaborate the existing models to improve decision making.

\section{IATs and marketing concepts/objectives}

In the marketing literature, market orientation is defined as the generation and dissemination of information and appropriate action based on market information (Kohli and Jaworski 1990). From a market orientation perspective, IATs have certain functional characteristics such as built-in environmental scanning and knowledge generation mechanisms, and the potential to exchange information about the market environment and the competition to enhance the strategic learning ability of the firm, leading to superior market orientation. According to the extant literature, superior market orientation leads to improvements in sales, customer satisfaction, and return on assets as compared to other companies that are not so market oriented (Kumar et al. 2011). These dynamic characteristics that are external to IATs constitute one of the dimensions of the IAT taxonomy. We broadly list these as market governance, customer orientation, competitor orientation, and learning orientation.

Emerging fast-paced marketing realities are linked to recent technological advances in various ways. The underlying principle is that explicit consideration of information technology can be grounded in the general notion of marketing as "a set of activities that facilitate exchange" (Glazer 1991). The economics of information literature studies the value created by information due to differences in customer search costs, and competitor and product heterogeneity. In a dynamic knowledge-based environment, companies may create value by profiling customers based on buyer-seller relationships, lifetime value, willingness to pay and preferences, and exploit product and brand dependencies based on the analysis of the market environment, the customer, the competitors, and the elements of a firm's own marketing mix (Abegglen and Stalk 1985; Greshoff and West 1998; Kumar and Reinartz 2012).

Market governance and market environment analysis Recent literature discusses the role of middle agents in terms of their control over interactions across various market participants in e-commerce (Bakos Yannis 1997). IATs as middle agents ensure good management of these markets by gathering information, laying out rules, and monitoring participants. We classify these as (a) market information agents, (b) market authentication agents, and (c) market maker agents.

Market information agents Expanded information regarding market players, and the demand and supply conditions in the market, is likely to result in higher efficiencies due to cost savings in terms of both inventory holding costs and marketing costs. The market information agents scan the market to collect information about the various players, changing environment, and regulations. They maintain a real-time database of market participants based on transactions to maintain reputation ratings and monitor transactions. Buyers will benefit due to the expanded information regarding product assortments, terms of sales, market prices, and saving of time and cost incurred in conducting searches. Sellers will benefit from real-time information about expanded market coverage opportunities and from information about customers, competitors, channels, and products. In the case of the selling of complex products and services, IATs decompose information and compile information from different sources to formulate different bundles for different segments to pursue price differentiation. Information regarding customer segments may also help in price differentiation. Further, the information on inventory holdings in different locations expedites customer service.

Market authentication agents Market governance requires protection of participants from opportunistic behavior and fraudulent practices in the market. The high number of transactions, no face-to-face contact, and dynamic markets make it difficult to trace participants to resolve disputes. It is particularly important in case of IATs where error (if not detected) may lead to severe damages. Authentication agents may provide checks and balances so that markets function smoothly. Comparative pricing and innovative communication strategies may also earn more consumer trust.

Market maker agents Modern markets are becoming technologically advanced, and the traditional human relational exchanges are increasingly being mediated or replaced by 
information technology. In this regard, IATs can play an important role as managers of such modern electronic markets. Further, IATs as market makers or as market managers play various important roles. These roles have been explained in the literature as (1) monitoring the market (e.g., creating and managing content; aggregating demand and matching buyers and sellers), (2) monitoring and managing participant opportunism, and providing secondary services such as logistics and insurance, and (3) self-participating in the electronic markets to build and update knowledge about the market functions and the market itself (Grewal et al. 2010). The middle agents represent matchmakers, market makers, and facilitators. Market maker agents such as GRAPPA (Generic Request Architecture for Passive Provider Agents) gather information from both sellers and buyers, whereas a matchmaker provides support for semi-structured data, assumptions, and constraints, and it enhances trust and privacy in e-marketing applications. A market maker agent's task is complex as it must facilitate, monitor, and govern transactions between multiple parties engaged in business. Further, the role of market maker agents is to establish laws and rules of engagement, and ensure enforcement to prevent and resolve disputes.

Customer orientation A rich stream of research in marketing posits that companies that adopt a customer orientation are more successful in the long run (Day 1999; Jaworski and Kohli 1993; Narver and Slater 1990). Customer orientation is defined as the philosophy of understanding and putting customers' interests first, while not excluding those of other stakeholders, for developing a long-term profitable and sustainable enterprise (Deshpande et al. 1993). IATs can unearth customer insights and interests by analysis of customer browsing behavior and previous purchases made by a customer. This customer knowledge discovery, using pattern recognition and marketing modeling techniques by IATs, could be in B2B or B2C contexts, and it can enhance marketing decision making and formulation of offers. The effectiveness of IATs will depend upon the availability of customer data that is current and captures customer information on various variables of interest. These IATs fall under the label of CRM agents, where their formal task is customer acquisition and customer retention.

Customer acquisition agents New customer acquisition and retention are perhaps the most difficult and defining steps for any business success (Němcová and Dvořák 2011). With faster information acquisition and the development of "apps, " customers are becoming more efficient with the purchase process. Companies now need to remain several steps ahead of customers to acquire and analyze customer data in real time to develop leads and convert those to prospects. Customer Intelligence Agents can use search engine optimization and social media to increase awareness and to identify and bring profitable customers to the website. They can capture and automatically update customer information. Customer Analysis Agents can analyze potential prospects' lifetime profitability based on past behavior and predicted future behavior. They can acquire profitable customers by using strategies to optimize customer lifetime values and customer acquisition costs.

Customer retention agents Anecdotal evidence and research in marketing (Kumar and Reinartz 2012) suggest that customer acquisition is almost five times as expensive as customer retention. In terms of customer retention, Recommendation Agents can provide insight into customer behaviors and increase satisfaction and loyalty, by offering superior customized products and services, based on customer preferences. Customer Negotiation Agents can design and implement retention and reward programs based on customer characteristics and purchase behaviors, while optimizing firm performance in terms revenues and profitability.

Competitor orientation Competitive intelligence has become increasingly important over the past several decades. According to Abegglen and Stalk 1985, preoccupation with the actions of competitors and creation and ruthless exploitation of competitive advantage are characteristics of successful Japanese companies. The advent of the Internet and e-commerce has made more information available to firms and their competitors in real time, and competitive intelligence has increased in importance over the last several decades. Gone are the days of competitor shopping where companies had to send "shoppers" to find information regarding competitor marketing mix. Nowadays, most information is available online either through the competitor's website, or else through third-party sites, and companies increasingly are moving towards more systematic competitive intelligence gathering and analysis.

Competitive intelligence agents Competitive intelligence is not limited to gathering information about the competitors marketing mix from time to time; it has become a regular activity, with companies undertaking it on a formal and dedicated basis. In fast changing product markets, competitor orientation is becoming increasingly important for companies to remain competitive and to survive. Markets remain abound of examples where a company came with a new product or marketing strategy, but quickly lost due to copying of product or marketing strategy by competitors with deeper pockets and established distribution structures (Taylor 1992). In such an environment, companies need to answer questions not only regarding the marketing mix of the competitors but also regarding underlying motivations, human and capital resources, channel partnerships, sourcing arrangements, etc. Information needs for competitive intelligence could be classified into (a) marketing mix level (e.g., pricing, promotion, product features 
and design, and patents), (b) competitor internal (e.g., sales statistics, cost data, manufacturing facilities and capacity, research and development, and financing), and (c) competitor strategic (e.g., expansion plans, key executives, and sourcing strategies).

At a very basic level, IATs can scan the market environment and mine information about competitors' finances and resources, which can be gathered from various financial reports and company balance sheets at a regular basis and provide important indicators for competitive advantage. Dynamic changes in product and pricing information can be obtained by IATs through monitoring competitors' websites, detecting changes, and analyzing patterns. This may not be possible for humans in dynamic environments. Other important aspects of competitive intelligence and analysis involve understanding competitors' sourcing and channel strategies. For example, IATs may analyze the communication patterns of competitors with suppliers, search keywords, and conduct content analysis of communications to recognize and understand patterns of communication and related activity. These may be difficult and may require continuous scanning and analysis of online communications.

Competitive analysis agents Increasing competition, quick accessibility, and the vast availability of information on the Internet make interpersonal communication increasingly important to marketers and consumers (Wiedmann et al. 2001). Consumers communicate and exchange information over the Internet at increasing rates and speeds (there is no traditional face-toface contact between consumers), and applications such as instant messaging, e-mail, text messaging, conferencing, chat rooms, online discussion groups, and blogging represent an emerging domain of social computing. According to a study by the Pew Internet and American Life Project (2010), the use of social network sites such as Facebook, MySpace, or LinkedIn increased for all online adults from 35 to $61 \%$ from 2008 to 2010. Social media, blogging, related communication and collaboration activities, and social aspects play important roles in enhancing business performance because they increase consumer insights and integrated marketing communication. When IATs capture keywords from these websites and adopt them in a company communication mix, they can enhance competitive advantages. Adaptive intelligent agents also can take into consideration others' opinions, which contain information as well as identify product attributes (Greshoff and West 1998). The classical face-to-face, word-of-mouth communication (WOMC) model might be translated and adapted to agentbased network WOMC (Tanimoto and Fujii 2003).

Competitive analysis agents collect competitive intelligence and also employ game theoretic strategies and tactics to respond to competitors' moves. Firm performance depends on its sources of SCA, e.g., better competitor information will result in better and timely responses to competitors' moves and higher performance. In knowledge-based environments, market sensing and market orientation become key firm resources for both tangible and intangible firm performance.

We can thus classify competitive analysis agents as follows:

Competitor intelligence agents Competitor information searching and data gathering regarding competitor marketing mix, competitor characteristics (including historical analysis of sector and competitor), and competitor strategies.

Competitor analysis agents Verifying the reliability of above information for various competitors and linking the above information to detect patterns.

Competitor response agents Constructing scenarios for present and future situations, and identifying and testing these scenarios to test proactive and reactive competitive strategies.

Learning orientation Learning organizations are flexible in their approach, and they continuously engage in experimentation and knowledge development (Senge 1990). "Working smart" is defined as optimal behavior to fit sales situations. This is based on a contextual view of intelligence, which requires making situation-appropriate decisions based on learning and capacity to engage in a wide range of selling behaviors and activities (Sujan et al. 1994). IATs can explore sales situations, and based on knowledge discovery mechanisms they can develop and utilize this knowledge in altering selling behavior and activities as appropriate to situational considerations. In fast-paced marketing environments, companies need to integrate knowledge about the environment, customers, and competitors, learn from successes and failure, and develop and implement innovative marketing strategies that work.

Market-mix analysis agents Previous research acknowledges the importance of privacy and security as key evaluations of website quality (e.g., Rust et al. 2004; Stewart and Pavlou 2002). IATs risk revealing sensitive information and compromising their safety if their information is leaked because of technical glitches or agent gullibility. Trust is an important dimension in marketing applications of IATs, and issues may remain unresolved due to lack of trust and explicit verification in exchanges. For example, a market-mix analysis agent could be used by companies to evaluate the effectiveness of the 4Ps. These agents may collaborate to create enhanced business performance for companies within the policy boundaries e.g., privacy and trust.

Collaboration agents Agents might collaborate with other agents to exploit their complementary skills or distribute tasks to attain higher efficiency, which would result in faster, higher 
quality output. Such collaboration might take the form of forecasting, capacity, order, inventory, or transportation collaboration. By helping consumers sift through loads of data and analyze information, IATs make purchase decisions a collaborative process of human-agent interaction. Both competence and trust can play roles in this collaborative process (Maes 1994). Huhns and Singh 1998 propose several agent types in an open environment cooperative information systems: user, broker, resource, and execution agents, as well as mediators and ontology agents. Liang and Huang 2002 suggest an intelligent collaborative agent (ICA) system for product development and customization that features (1) intelligence, because the agent can customize and adapt to changes in the environment; (2) autonomy, such that the agent takes initiative and controls its actions; and (3) cooperation, because the agent makes suggestions, requests information, and cooperates with others. An ICA can also perform complex tasks by combining atomic modules. It serves four roles: (1) explore (e.g., Web crawler) - searching and locating product modules; (2) optimize- optimizing the module combination based on customer requirements and engineering constraints; (3) schedule-monitoring the agent's ability to meet customer specifications; and (4) manage - maintaining a module database, delivering status messages, and communicating with the various entities.

\section{A framework for IAT adoption and sustainable competitive advantage}

Understanding the drivers for adoption of IATs and integrating them with organizational activities may sustain and augment market orientation, which would ensure superior firm performance. The diffusion of innovation theory (Bass 1969; Rogers 1995 ) provides conceptual and theoretical foundations for the adoption of intelligent agent technologies.

One of our aims in this paper is to determine the drivers that affect the need for adoption and utilization of IATs and to understand how IAT utilization may help in achieving SCA. To determine these issues, based on the above theory, the key explanatory variables in our proposed framework include: market environment, IAT characteristics, customer characteristics, product characteristics, firm resources and capabilities, and industry/market dynamics. The key dependent variable is adoption/utilization of IATs by a firm. Lastly, we investigate the relationship between IAT adoption and firm performance based on marketing literature (McAfee and Brynjolfsson 2008). Besides the main effects, we also discuss the moderating effects of market environment on IAT adoption and its ultimate effect on SCA. We develop a framework illustrating the drivers for IAT adoption and its ultimate effect on SCA (Fig. 2).

\section{Market environment}

Marketers in the twenty-first century are impacted by technological, economic and regulatory trends (Kotler 1999). Information technology and the Internet have led to an increasingly knowledge-based business environment that is characterized by: (1) diminishing information search costs, (2) diminishing information asymmetry, (3) increasing cost transparency, and (4) altered communication models (Varadarajan and Yadav 2002). Companies are moving to exploit the expanded marketing opportunities created by these changes.

Over the last several decades there has been a normative shift in the business environment characterized by novel information flows, evolving online search features, and price discovery mechanisms that has altered established business paradigms and has led to a structural shift in company growth strategies. The market environment, coupled with changing economic conditions, is becoming increasingly knowledge based, one that creates, disseminates, and uses knowledge, thereby making knowledge a key source of competitive advantage (Bedford 2012). An important change is that while information is more readily available, at the same time, the rapidly expanding technological environment is increasing in complexity. In this sense, IATs can search and screen relevant information, assisting companies in finding information about consumers and offering personalized products and services (Murthi and Sarkar 2003), thus providing incentives to companies by expanding capabilities to provide superior value propositions.

In knowledge-based market environments, privacy and security are the primary consumer concerns and must be addressed for the successful and continued application of IATs, and to enhance the effectiveness of interactive media (Rust et al. 2004; Stewart and Pavlou 2002). Consumers might accuse agents of collecting personal information without their knowledge, building profiles, or tracking electronic footprints, which could make them reluctant to disclose personal information if the seller agents manipulate the buyer's agents to obtain sensitive information. Other concerns include allegations of price fixing, made easier by the exchange of real-time information, and the monitoring of competitors.

While privacy protection laws (e.g., Privacy Act 1974; Computer Matching and Privacy Act 1988) address existing issues, new and unforeseen issues could emerge as IATs develop and become more popular. For instance, novel methods of information piracy and leakage may be much broader and greater in scale. Policies may not be in place for such previously unknown methods. This situation creates the need for formulating appropriate policies and regulations that are more exhaustive. In addition to private companies and consumers, governments can play important roles in the development, support, and early adoption of IATs through research, clearer policies, and regulations. Evolution of rules and regulations 
Fig. 2 Marketing IAT adoption and sustainable competitive advantage: an integrative framework

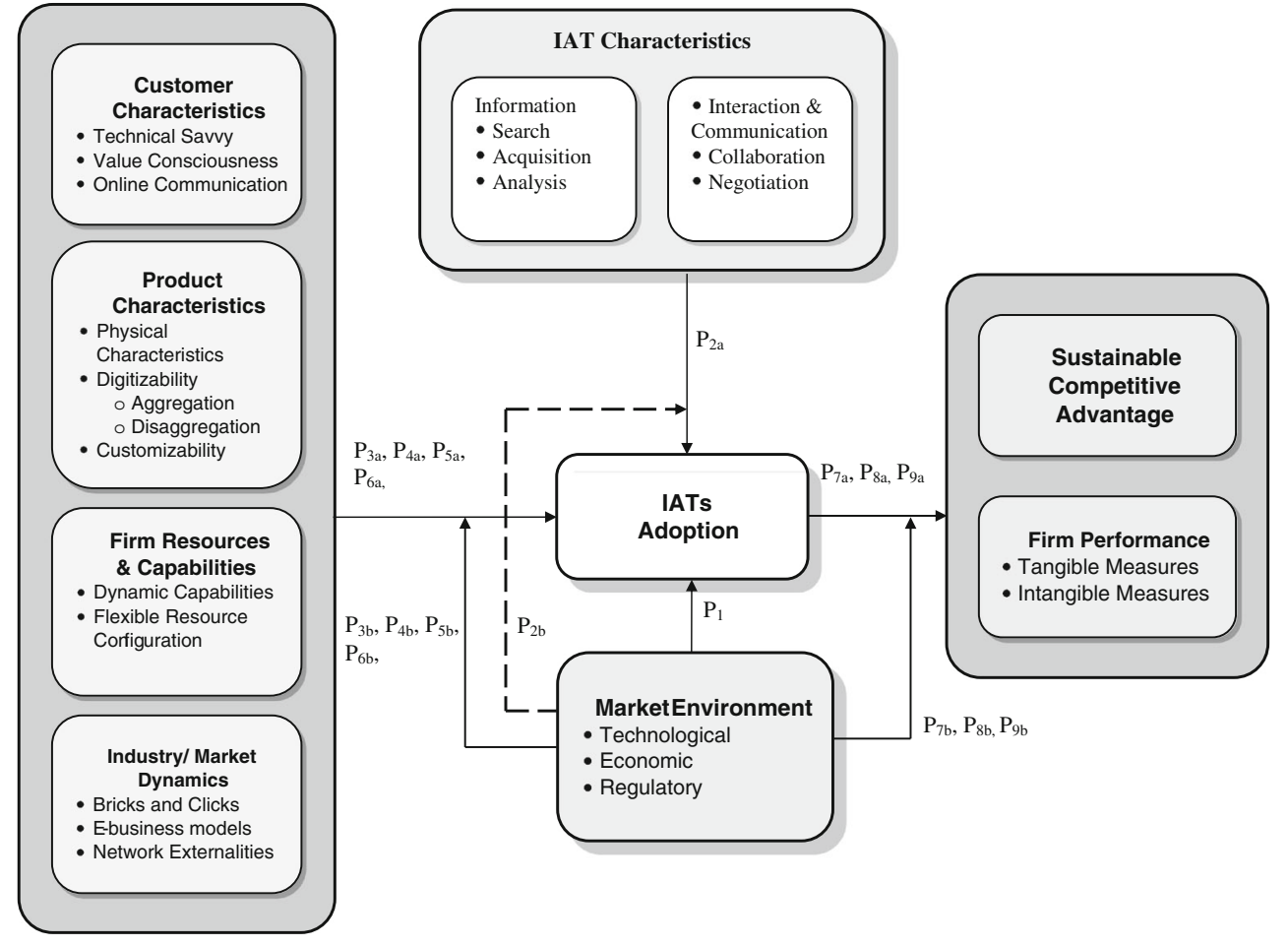

IAT adoption is linked not only to their compatibility, ease of use, and relative advantage but also to how well their characteristics can be observed, communicated, and imitated. Based on our previous discussions, we argue that the higher that the IATs are tailored to companies' needs for information search, acquisition, and analysis, and the greater companies' communication and collaboration abilities, the higher the utilization of IATs will be.

P2a: The greater the need for IAT characteristics (information search, acquisition for consumer profiling and personalization, information analysis, heterophily among a firm's stakeholders in terms of online communication and interactivity, and online collaboration between a firm and its stakeholders), the greater the need of adoption of IATs by a firm.

Environmental uncertainty refers to changing technology and evolving political, economic regulatory environments, and marketing norms which may affect the speed of IAT adoption. Marketing applications of IATs by firms are, however, moderated by market environments such as technological availability, economic need, and regulatory challenges (Lynch and Ariely 2000).

According to contingency theory, organizations are open systems and need to balance their internal needs with environmental circumstances (Morgan 1997). Environmental complexities can be broadly divided into economic (macro-economic forces), regulatory, and technological (innovations). Growing environmental complexities provide context in 2004). 
which one conceives or adapts one's business model by taking into account various design drivers (e.g., new technologies), and design constraints (regulatory trends) (Osterwalder 2009).

P2b: The relationship between IAT characteristics (need for information search, acquisition for consumer profiling and personalization, information analysis, heterophily among a firm's stakeholders in terms of online communication and interactivity, and online collaboration between a firm and its stakeholders) and adoption of IATs by a firm will be moderated by market environment (e.g., technological, economic, and regulatory).

Customer characteristics and adoption of IATs

Changing customer characteristics and the increasingly dynamic online business environment not only present a considerable challenge for markets to extract value, but also provide unprecedented opportunities for competitive advantage and growth. As consumers become more technically savvy, value conscious, and actively engaged in online communities, the need for using intelligent agents for customer support increases among firms. The role of changing customer attitudes in the adoption of new technologies is well documented in the literature. Customers' attitudes, search behavior, and purchase intentions develop sequentially or hierarchically (MacKenzie and Lutz 1989). Customers not only search the web for product information, but they are also increasingly purchasing products and services online. These provide unprecedented opportunities for companies to promote and distribute products and services over the web. Companies such as Amazon, Netflix, Priceline, and Groupon not only provide products and services but also collect customer data on the web continuously. Market environment (e.g., technological and regulatory changes) impacts consumer online communication capabilities. Firms adopt IATs to interact with customers online; however, such effects are moderated by the market environment based on the contingency theory and are more pronounced in an information-rich technological, economic, and regulatory environment.

P3a: The greater the technical savvy, value consciousness, and online interaction and communication of customers, the higher the need for the adoption of IATs by a firm.

P3b: The relationship between consumer characteristics (e.g., technical savvy, value consciousness, and online interaction and communication) and the need for IAT adoption by a firm will be moderated by the market environment (e.g., technological, economic, and regulatory).

Product characteristics and adoption of IATs

Products can be classified on a continuum from information independent (e.g., traditional products) to semi-dependent (information is valuable in the bundle but secondary to the main product, e.g., electronic equipment) to information dependent (information is most valuable in the main product, e.g., magazines) and smart (intelligent information is the main valueadded or marketable product, e.g., self-driving cars, recommendation systems) (Glazer 1991). Overall product characteristics, such as physical characteristics, digitizability, and customizability, have important implications for IAT adoption (Balasubramanian et al. 2000).

Physical characteristics (De Figueiredo 2000) classifies products based on physical characteristics into commodities, quasi-commodities, look and feel, or look and feel with variable quality. Although currently IATs easily can compare prices of commodity and quasi-commodity products (e.g., books, CDs), they have a harder time discriminating among emotional and experiential goods, which depend on customers' changing tastes. Whereas agents can learn choice rules such as constraint-based rules, pattern recognition, and conjoint analysis from certain algorithms, they cannot account for sudden shifts in fashion and taste unless they are adaptive in nature. The adaptive IATs, as demonstrated by recommendation systems, however, are not only capable of product recommendation but also of customization and personalization in case of certain products.

Digitizability How can IATs replace the sensation of touching a product, trying it on, or testing it before making a purchase decision? Various researchers discuss different products' amenability to the Internet (Bakos Yannis 1997; Varadarajan and Yadav 2002). Some products that seemingly are not amenable could be digitized, so that the IATs would offer superior configurations and testing in simulated environments. For example, digital products that can be marketed as either aggregated or disaggregated may benefit from the use of IATs, which can configure and price optimal product bundles.

Customizability (Peppers et al. 1999) advocate mass customization for products ranging from books to computers. IATs have the potential not only to enable this mass customization of information products but also to provide personalization that can ensure a sustainable competitive advantage to those companies with a better understanding of the 
different micro-segments and their demands. Varadarajan and Yadav 2002 discuss how digital products might be customized through seamless integration into aggregated digital products. The exploration of the feasibility of acquiring providers of complementary products assumes even greater importance for businesses that compete primarily in the virtual marketplace. As the market environment becomes more advanced we expect even higher adoption of IATs by companies. As discussed previously, based on the contingency theory we expect a moderating effect of the environment and propose the following:

P4a: The greater the need for digitizability and customizability of a firm's products, the higher the need for adoption of IATs by that firm.

P4b: The relationship between the need for digitizability and customizability of products and the need for adoption of IATs by a firm will be moderated by the market environment (e.g., technological, economic, and regulatory).

Firm resources and capabilities and adoption of IATs

According to the resource-based theory of the firm, gaining a competitive advantage requires that the firm possess resources that are valuable, rare, inimitable, and non-substitutable (VRIN). Barney 2001 argues that a firm's competitive advantage is derived from its unique bundle of resources that are difficult for competitors to duplicate. The resource-based view (RBV) classifies resources as (1) managerial resources, (2) input based resources, (3) transformational resources, and (4) output resources (Menguc and Auh 2006).

As an extension of the RBV, dynamic capability theory posits that companies search for new resources and/or new ways of utilizing existing resources to build, integrate, and reconfigure internal and external competencies to achieve a competitive edge in a knowledge-based economy. Dynamic capabilities thus reflect a firm's processes to achieve new and innovative forms of competitive advantage given their resources, path dependencies, and market positions (Teece et al. 1997).

Eisenhardt and Martin 2000 emphasize the importance of dynamic capabilities as a means to provide quick responses to mission-critical applications in informationintensive environments. IATs play an important role as information resources that involve the nature and amount of information possessed by the firm about individual customers, competitors, and other stakeholders. By acquiring and analyzing customer and competitor information, IATs gain knowledge about customer segments and then use that knowledge to offer customized solutions and gain competitive advantage.

Furthermore, in light of the highly competitive realities and demand uncertainties faced by companies, strategic flexibility of firms depends on resource identification, acquisition, and deployment capabilities (Johnson et al. 2003). While committed resources can reduce cost outlays when demand is predictable, flexible resource configuration provides companies a buffer in meeting demand fluctuations (Hansen and Mowen 2011). We advance the idea that optimal flexibility in firm resource configuration, pertaining to changes in product design, product mix, the rate of production or resource usage in response to market conditions, may affect firm costs and performance. Successful companies (e.g., Amazon, eBay) reap rich dividends from the excellence of their technological competence and their integration of marketing with backend support systems. IATs can reinforce and augment these technical capabilities to optimize firm resource configuration. This can be done by better monitoring of resource usage based on accurate assessment of changes occurring due to supply and demand fluctuations, product customizations, and changes in the marketing mix. Moreover, as discussed previously, based on contingency theory we expect a moderating effect of environment and thus propose:

P5a: The greater the dynamic capabilities and flexible resource configuration of a firm, the higher the need for adoption of IATs by that firm.

P5b: The relationship of dynamic capabilities and flexible resource configuration and the need for adoption of IATs by a firm will be moderated by the market environment (e.g., technological, economic, and regulatory).

Industry/market dynamics and adoption of IATs

Internet technology has created new industries and markets such as online auctions and digital marketplaces (Porter 2001). The traditional marketing approach is changing in response to the recent emergence of e-business models with unique selling propositions, such as Amazon (selection), virtual vineyards (specialized information, trusted advice), Priceline (reverse auctions), and eBay (auctions). These models support a fundamental shift in the industry toward a knowledge-based economy. E-business models may be understood as the structure of a firm and its network of partners, which it uses to create, market, and deliver value and relationship capital to one or several segments of customers and thus achieve long-term and sustainable profitability (DubossonTorbay et al. 2002). Various e-businesses adopt different 
business models and formats in terms of content (e.g., nytimes), community (tripod), and commerce (Amazon), though all of them can benefit from innovative IAT applications.

These new e-business models necessitate a wide range of supportive technologies (Timmers and Gasós 2001), some of which IATs can address. For example, e-auction sites such as eBay attract millions of consumers looking for adventure, entertainment, and a bargain. Analysis of such data in real time is extremely difficult and humanly impossible. Different consumers bid for a product, but IATs enable them to bid for various products across several different websites. IATs (e.g., auctionrover, auctionwatch, biddersedge) also track several online auctions concurrently (Warkentin et al. 2001). IATs estimate and formulate strategies based on inputs from various data sources, pattern recognition, and mathematical modeling and can bid up prices to take possession of a range of items, which results in an efficient marketplace.

In collaborative developmental efforts, members have strong incentive to participate and contribute due to the benefit of leading others who are likely to follow (Zhao et al. 2007). In addition, companies have network externalities, in terms of adopting common standards for business transactions. Due to the presence of network externalities or "path dependence" among end users, firms have an incentive to develop and adopt IATs better and faster than others. Moreover, environmental complexities can moderate adoption of IATs in case of new business models.

P6a: The greater the emergence of newer business models and network externalities, the higher the need for adoption of IATs by companies in that industry.

P6b: The relationship between the emergence of newer business models and network externalities and the need for adoption of IATs by a firm will be moderated by the market environment (e.g., technological, economic, and regulatory).

Sustainable competitive advantage and adoption of IATs

The final question that we examine in this paper is whether adoption of IAT can translate into sustainable and superior business performance. Research points to the dynamic capabilities of companies as sources of fundamental competitive advantage (Eisenhardt and Martin 2000). Based on the resource-based view of the firm, Menguc and Auh 2006 highlight the dynamic capability-generating capacity of market orientation by taking an internal approach that focuses on firm resources. Market orientation uses the fundamental premise of being close to the market through elaborate market sensing, information generation, assimilation, and dissemination mechanisms (Jaworski and Kohli 1993). Market orientation can be augmented and transformed into a dynamic firm capability through IAT adoption. Because knowledge is the fundamental source of competitive advantage, companies that learn quickly are likely to perform best in dynamic environments.

Research also considers how providing more product information and customization increases profitability (Peppers et al. 1999; Porter 2001). Companies that use IATs acquire the dynamic capability to customize their offerings and offer highly differentiated products suited to individual customers' needs. Regarding potential downward pressures on price (caused by IATs), researchers demonstrate that retailers can shift the emphasis to quality cues rather than price (Lynch and Ariely 2000). The benefits achieved from customization and higher margin sales complement lower margins sales, i.e., higher margin sales may result from better understanding of customer needs and differentiation, these may complement the lower margin sales due to lower prices in tough competitive situations (Chen and Sudhir 2004).

Innovative agent technologies and communication strategies may counter consumer information overload. Because they provide more relevant information, added capability for personalization, and the ability to handle complex tasks, IATs help companies maintain a sustainable competitive advantage. Thus, the adoption of IATs will have synergistic effects as a fundamental source of competitive advantage.

P7a: The greater the adoption of IATs by a firm in a knowledge-based environment, the higher the sustainable competitive advantage of that firm.

P7b: The relationship between the adoption of IATs by a firm in a knowledge-based environment and the degree of sustainable competitive advantage of a firm will be moderated by the market environment (e.g., technological, economic, and regulatory).

Firm performance and adoption of IATs

Tangible measures With IATs, both companies and consumers can access information simultaneously from various websites and sort the information into meaningful categories. Research shows that though shopbots generally push prices downward, carefully applied agents can provide many opportunities to target micro-consumer segments based on their willingness to pay, maintain relationships, and leverage brand names (Iyer and Pazgal 2003). According to Smith 2002, agents can help retailers find ways to maintain their price differentiation while better targeting consumers with microsegmentation. Retailers thus have greater opportunities to 
differentiate their products because of their careful understanding of their target market's preferences. The use of notification and recommendation agents also help retailers up- and cross-sell products, which results in higher sales volumes and market shares, as well as more satisfied and fulfilled customers. Furthermore, IATs protect market share through careful competitor analysis and defense. Agents can increase ROI by reducing marketing costs because they support far more customers than a human sales or technical representative. Automated order fulfillment mechanisms reduce inventory requirements and drastically cut down fulfillment times. For example, Dell uses IATs to collaborate with suppliers in the online, real-time assembly of complex computers, which saves it valuable time and drastically cuts down its inventory levels.

P8a: The greater the utilization of IATs by a firm in a knowledge-based economy, the higher the firm's tangible performance.

P8b: The relationship between the utilization of IATs by a firm in a knowledge-based economy and the firm tangible performance will be moderated by the market environment (e.g., technological, economic, and regulatory).

Intangible measures Firm performance could be incrementally attributed to intangible aspects such as developing and maintaining customer and firm relationships (Palmatier et al. 2007). Consumer attraction and retention are relatively difficult online because buyers can use intelligent agents to search for better deals. However, Reibstein 2002 finds that customer service support is a key to customer loyalty, and agents can enhance customer service by increasing the quality and quantity of communication and interaction. The role of trust as a moderator of marketing relationships (Moorman et al. 1993; Schurr and Ozanne 1985 ) is crucial for negotiations, especially in the electronic marketplace, because buyers and sellers do not engage in face-to-face interactions. IATs enhance trust through their accurate and complete information and advice. Some trust-building cues include privacy, security, source credibility, guarantees, third-party and celebrity endorsements, user-friendly interfaces, keeping small promises, and expertise descriptions, among others (Urban et al. 1999). These elements feed into IATs and enable micro-segmentation, which offers customers customization of displays, information acceleration, and interactions in a virtual store. This proposed virtual advisor thus builds trust, and most customers appear to be willing to pay for the service.
Finally, research indicates that consumers use brands as a proxy for retailer credibility in non-contractible product and service bundles. Because shopping bots imitate the idealized setting assumed in common choice models, regular use of shopping bots over time may not actually cause consumers to rely more on price; instead, "branding will be even more important in Internet markets for less homogenous goods and services, especially when they have important noncontractible characteristics" (Smith and Brynjolfson 2001, p. 556).

P9a: The greater the adoption of IATs by a firm in a knowledge-based economy, the higher the firm's intangible performance.

P9b: The relationship between the adoption of IATs by a firm in a knowledge-based economy and the firm's intangible performance will be moderated by the market environment (e.g., technological, economic, and regulatory).

In summary, IATs possess autonomy or the ability to sense and proactively or reactively interact with other agents, humans, or social systems of agents in dynamic environments. Furthermore, IATs can handle complex tasks of communication, coordination, cooperation, negotiation, and competition to achieve goals (Fasli 2007). Table 2 provides examples of marketing applications of IATs.

\section{Discussion}

Intelligent agent technologies and their marketing applications are not without limitations. As agents are designed by humans they may suffer from and reflect underlying constraints and errors that may exist, but may only be evident in rare instances. Another limitation that is evident from the literature is that the applications studied and developed provide piecemeal solutions, and the complexities of providing holistic solutions may be very difficult to overcome. While agent applications may provide solutions to specific business problems, work is still needed to validate these solutions when considering actual deployment, as agent applications do not have complete global knowledge. Furthermore, the principal's objectives may change and may not have been communicated to the agent. Thus trust and delegation issues are important. This research is the first comprehensive step in developing a marketing-centric definition, taxonomy, and framework to understand and address some of these limitations. 
Implications for marketers

The increasing amount of information and the increasingly dynamic online business environment present a huge challenge for markets to extract value, and also provide unprecedented opportunities for competitive advantage and growth. IATs should not be taken lightly as they have the potential to fundamentally transform the future of marketing based on various factors discussed in this section.

Increased learning and insights Agents will grow more intelligent in the future and perform ever more complex tasks by collaborating, which in turn will make marketing even more efficient and effective. They also may increase the intensity of competition and consumer power due to lower search costs. Consumer adoption of IATs may exert downward pressure on prices for undifferentiated products, but strong price/quality perceptions and branded variants ensure price variation in markets. For attributes and intangibles (e.g., service, delivery time, privacy, security) that are difficult to judge, consumers likely will rely more on brands or firm name (Smith and Brynjolfson 2001).

Expanded search abilities and faster decisions Compared with human online search processes, IATs increase search abilities that may result in more options to choose from. They provide increased efficiencies in the areas of information handling and retrieval, inventory and relationship management, and offer consumer value in the form of more convenience, better information, and better selection. Consumers gain more power with the advent of software search agents that remove the tedium of the buying process.

Improved effectiveness and efficiency Researchers and practitioners recognize the need to leverage the effectiveness of computer-based innovations for customer use ( $\mathrm{Zhu}$ et al. 2007). The value of IATs is derived not only from their price comparisons but also their product and service recommendations, which are based on each customer's needs. They also offer personalization potential. For instance, agents can learn consumer preferences and constraints, and create specific mixes of digital recordings. Similarly, agents also may assist consumers in complex tasks, such as configuring and customizing their computer systems on the basis of their preferences and selection criteria. While other agents might scour news websites to create customized newsletters, IATs may lead to an expanded choice set, better matches, increased market efficiency, cost reductions, and ultimately higher social welfare. On the other hand, given

Table 2 Examples of intelligent agent technologies: marketing applications

\begin{tabular}{|c|c|c|c|c|}
\hline Activity & Definition & Application & Representative agent/Sites & Implications \\
\hline $\begin{array}{l}\text { Information search } \\
\text { (consumer } \\
\text { decision making) }\end{array}$ & $\begin{array}{l}\text { Quickly \& easily accessing } \\
\text { information (Diehl et al. 2003; } \\
\text { Greshoff and West 1998) }\end{array}$ & $\begin{array}{l}\text {-Product search } \\
\text {-Price search } \\
\text {-Attribute search }\end{array}$ & $\begin{array}{l}\text { www.copernic.com, www.BizRate.com, } \\
\text { www.shopping.com, www.bankrate.com, } \\
\text { www.mysimon.com, www.dealtime.com. }\end{array}$ & $\begin{array}{l}\text { Classify based on } \\
\text { consumers' } \\
\text { information search } \\
\text { patterns. }\end{array}$ \\
\hline $\begin{array}{l}\text { Information } \\
\text { acquisition }\end{array}$ & $\begin{array}{l}\text { Moving information from its source } \\
\text { to its appropriate destination } \\
\text { (Iacobucci et al. 2000). }\end{array}$ & $\begin{array}{l}\cdot \text { Notification } \\
\text { •Configuration }\end{array}$ & $\begin{array}{l}\text { www.amazon.com, } \\
\text { www.bfads.net, } \\
\text { www.pricewatch.com. }\end{array}$ & $\begin{array}{l}\text { Optimize data } \\
\text { acquisition process. } \\
\text { Make it cost } \\
\text { effective. }\end{array}$ \\
\hline $\begin{array}{l}\text { Information } \\
\text { analysis }\end{array}$ & $\begin{array}{l}\text { Converting raw information into } \\
\text { useful outcomes. Arranging } \\
\text { information } \\
\text { in a way that responds to a need. }\end{array}$ & $\begin{array}{l}\text {-Learning } \\
\text {-Personalization } \\
\text {-Product } \\
\text { brokering } \\
\text {-Merchant } \\
\text { brokering }\end{array}$ & www.broadvision.com. & $\begin{array}{l}\text { Optimize data analysis } \\
\text { process. Make it } \\
\text { useful. }\end{array}$ \\
\hline $\begin{array}{l}\text { Online } \\
\text { communication } \\
\text { \& interaction }\end{array}$ & $\begin{array}{l}\text { Facilitating the exchange of } \\
\text { information. Intelligent agents } \\
\text { communicating with one } \\
\text { another (Hodgdon 1997) }\end{array}$ & $\begin{array}{l}\text { Data-driven } \\
\text { communication }\end{array}$ & www.amazon.com . & $\begin{array}{l}\text { Enhance customers' } \\
\text { online experience. }\end{array}$ \\
\hline Collaboration & $\begin{array}{l}\text { Harmonizing activities performed } \\
\text { by multiple entities toward a } \\
\text { common goal (Hodgdon 1997) }\end{array}$ & $\begin{array}{l}\text { Coordinating \& } \\
\text { collating }\end{array}$ & $\begin{array}{l}\text { PERSUADER at Carnegie Mellon. } \\
\text { www.ebay.com, www.saffronart.com, } \\
\text { FLECSE (Flexible environment for } \\
\text { collaborative software engineering) }\end{array}$ & $\begin{array}{l}\text { Enhance customers' } \\
\text { online experience. }\end{array}$ \\
\hline Negotiation & $\begin{array}{l}\text { Detecting \& interpreting signals \& } \\
\text { responding }\end{array}$ & $\begin{array}{l}\text { Sensing \& } \\
\text { responding }\end{array}$ & $\begin{array}{l}\text { www.ebay.com, www.saffronart.com, } \\
\text { www.priceline.com, PERSUADER at } \\
\text { Carnegie Mellon. }\end{array}$ & $\begin{array}{l}\text { Establish product } \\
\text { pricing mechanism. }\end{array}$ \\
\hline
\end{tabular}


their operant nature, they may lead to biased decisions and may be susceptible to inappropriate information extraction and fraud.

Potential challenges Different rates of technology adoption among consumers make it difficult to predict how quickly people will change their behaviors in response to IATs. Montgomery et al. 2004 find that a significant percentage of shoppers still generate higher utility from shopping at their favorite stores than using a shopping agent. Legal and privacy issues, error magnification, lack of control, and trust represent other important concerns regarding the adoption of IATs. To make the most of their potential, IATs will have to overcome various challenges. For example, the reliability and validity of agent information that determines the quality and fit of a product must increase. In addition, agents must be designed to address the question of standardized product and service representation to facilitate their use across companies and industries. Such standardization may offer a competitive advantage to companies that use IATs and fuel further rapid growth in electronic commerce.

Privacy Researchers acknowledge the importance of privacy and security as key evaluations of website quality (e.g., Rust et al. 2004; Stewart and Pavlou 2002). Restricted disclosure, owner-centered context management, anonymity, and early detection of misuse are some commonsense strategies that can be adapted to protect privacy (Titkov et al. 2006). Additionally, IATs provide security through high-level encryptions and pseudonomity (Goldberg 2000; Kobsa and Schreck 2003). However, because privacy remains a major challenge to the use of agent applications, the adoption of strong privacy models and assurances, and education about security measures should influence decisions to adopt IATs.

\section{Directions for future research}

Undoubtedly, advances in information technology are evolving at a fast pace. As we move toward a knowledge economy, the role of IATs should become more noteworthy. Our research provides a taxonomy, a framework, and a set of theoretically based propositions that are suitable for applications of IATs in marketing. Further research is needed to test these propositions both in controlled and field settings across different types of scenarios. Because of rapidly changing and highly competitive markets, further research should attempt to understand what drives or constrains its adoption by consumers. In addition, how do IATs influence marketing practice? For example, to what extent do IATs encourage new pricing strategies (e.g., partitioned prices), new products (e.g., branded variations, bundled or unbundled products, customization), competitive landscapes (e.g., new business models, competitor analysis and defense, merchant brokering), and consumer choice processes (e.g., negotiation, collaborative filtering, personalization)?

The marketing role of IATs is not without challenges. Business information is sensitive, and sharing it could result opportunistic exploitation (Frazier et al. 2009). When intelligent agents communicate, cooperate, or negotiate, they reveal selective information and make judgments about information provided by other interacting agents. As IATs learn individual consumer preferences, there is a danger of over-exploiting customer information, for example, willingness to pay. Other issues include privacy, misdirection, inaccurate information to customers about inventory levels, and prices. Some of these issues have been addressed in the marketing literature in different but related contexts (e.g., see Frazier et al. 2009), and need to be seriously considered by companies adopting IATs.

The uncertainty about agent performance creates other important challenges such as reliability/security issues, trust issues, and legal requirements. IATs can introduce some problems along with their various benefits, (e.g., privacy concerns, identity theft, cyber-crimes, misleading information, copyright infringement, counterfeiting, fraud, malicious mischief, unpredictable side effects). Research is needed to understand contract violations by IATs, and principals and enforcement (Antia and Frazier 2001). The perceived benefits, costs, and risks of sharing information among IATs need to be evaluated (Frazier et al. 2009). Digital certification and authentication systems, as well as high levels of encryption, may allay some of these concerns. Other problems may self-correct in the marketplace with increasing consumer use, concentrated Internet markets, and improvements in the IATs themselves (Smith 2002).

The pervasiveness of information overload in the marketplace means that agents will continue to have a major influence on marketing practice through expanded opportunities (e.g., social interaction, cross-selling, cost reductions) (Köhler et al. 2011). The taxonomy and the framework developed and presented in this research could be considered as a basis for the future of marketing adoption and utilization of IATs. The impact of the technological advancements on marketing, however, is much more complex since we do not always understand how it influences customers' attitudes and behaviors.

Acknowledgments We thank the editor, and the reviewers for their valuable guidance in revising this manuscript. We also thank Andrew Petersen, Denish Shah, Insu Park, Ifitkhar Sikder, Gayatri Shukla and Hannah Kim for their comments on the earlier version of this manuscript. We also thank Renu for copyediting this manuscript. 


\section{Appendix}

Table 3 Selected definitions of intelligent agent technologies (IATs)

\begin{tabular}{|c|c|c|}
\hline Author & Definition of intelligent agent technology & Characteristics of IATs \\
\hline (Wooldridge 2002, p. 15) & $\begin{array}{l}\text { [c] omputer systems/programs situated in some environment, } \\
\text { that [are] capable of autonomous action in this environment } \\
\text { in order to meet its design objectives. IATs possess the properties } \\
\text { of learning, autonomy, social ability, reactivity, and pro-activeness }\end{array}$ & $\begin{array}{l}\text { Autonomous actions, } \\
\text { learning, social } \\
\text { ability, reactivity, pro- } \\
\text { activeness. }\end{array}$ \\
\hline $\begin{array}{l}\text { (Russell and Norvig } \\
\text { 1995, } \\
\text { p. 33) }\end{array}$ & $\begin{array}{l}\text { An agent is anything that can be viewed as perceiving its environment } \\
\text { through sensors and acting upon that environment through effectors }\end{array}$ & Sensory \\
\hline Maes 1991 & $\begin{array}{l}\text { Autonomous agent are computational systems that inhabit some } \\
\text { complex dynamic environment, sense and act autonomously in } \\
\text { this environment, and by doing so realize a set of goals or tasks } \\
\text { for which they are designed. }\end{array}$ & Goal specific \\
\hline (Smith et al. 1994) & $\begin{array}{l}\text { Let us define an agent as a persistent software entity dedicated to a } \\
\text { specific purpose. 'Persistent' distinguishes agents from subroutines; } \\
\text { agents have their own ideas about how to accomplish tasks, their own } \\
\text { agendas. 'Special purpose' distinguishes them from entire multifunction } \\
\text { applications; agents are typically much smaller. }\end{array}$ & Task-specific \\
\hline (Hayes-Roth 1995) & $\begin{array}{l}\text { Intelligent agents continuously perform three functions: perception } \\
\text { of dynamic conditions in the environment; action to affect conditions } \\
\text { in the environment; and reasoning to interpret perceptions, solve problems, draw inferences, } \\
\text { and determine actions. }\end{array}$ & Reasoning \\
\hline (Coen 1994) & $\begin{array}{l}\text { Software agents are programs that engage in dialogs [and] negotiate and } \\
\text { coordinate transfer of information }\end{array}$ & Negotiating and informative. \\
\hline (Brustoloni 1991) & $\begin{array}{l}\text { Autonomous agents are systems capable of autonomous, purposeful action } \\
\text { in the real world }\end{array}$ & Purposeful \\
\hline $\begin{array}{l}\text { (Franklin and Graesser } \\
\text { 1996) }\end{array}$ & $\begin{array}{l}\text { An autonomous agent is a system situated within and a part of an } \\
\text { environment that senses that environment and acts on it, over time, in } \\
\text { pursuit of its own agenda and so as to affect what it senses in the future. }\end{array}$ & Task specific \\
\hline
\end{tabular}

\section{References}

Abegglen, J. C., \& Stalk, G., Jr. (1985). Kaisha the Japanese corporation (2nd ed.). New York: Basic Books Inc.

Aizawa, A. (2002). An Approach to Microscopic Clustering of Terms and Documents. In M. Ishizuka \& A. Sattar (Eds.), Pricai 2002: Trends in Artificial Intelligence. Tokyo: Springer.

Antia, K. D., \& Frazier, G. L. (2001). The severity of contract enforcement in inter-firm channel relationships. Journal of Marketing, 65(October), 67-81.

Brustoloni, J. C. (1991). Autonomous agents: characterization and requirements. Carnegie Mellon Technical Report CMU-CS-91204, Carnegie Mellon University 1991.

Bace, R. G. (2000). Intrusion detection. Indianapolis: Macmillian.

Bakos Yannis, J. (1997). Reducing buyer search costs: implications for electronic marketplaces. Management Science, 43(12), 1613-1630.

Balasubramanian, S., Krishnan, V. V., \& Sawhney, M. (2000). New Offering Realization in the Networked Digital Environment. In J. Wind \& V. Mahajan (Eds.), Digital Marketing (pp. 310-338). New York: Wiley.

Barney, J. B. (2001). Is the resource-based view a useful perspective for strategic management research? yes. Academy of Management Review, 26(1), 41-56.
Bass, F. M. (1969). A new product growth model for consumer durables. Management Science, 15(January), 215-227.

Bedford, D. (2012). "Expanding the definition and measurement of knowledge economy -integrating triple bottom line factors into knowledge economy index models and methodologies" Proceedings of the European Conference on Intellectual Capital, 67-74.

Beverland, M. B., Kates, S. M., Lindgreen, A., \& Chung, E. (2010). Exploring consumer conflict management in service encounters. Journal of the Academy of Marketing Science, $38,617-633$.

Binmore, K., \& Vulkan, N. (1999). Applying game theory to automated negotiation. Netnomics, 1(1), 1-9.

Bodapati, A. V. (2008). Recommendation systems with purchase data. Journal of Marketing Research, 45(1), 77-93.

Boehm, B., \& Turner, R. (2005). Managing challenges to implementing agile processes in traditional development organizations. IEEE Software, 22(5), 30-39.

Chaib-Draa, B., \& Dignum, F. (2002). Trends in agent communication language. Computational Intelligence, 18(2), 89-101.

Chang, J.-H., Lee, J. W., Kim, Y., \& Zhang, B.-T. (2002). Topic Extraction from Text Documents Using Multiple-Cause Networks. In M. Ishizuka \& A. Sattar (Eds.), Pricai 2002: Trends in Artificial Intelligence. Tokyo: Springer. 
Chen, D.-N., Jeng, B., Lee, W.-P., \& Chuang, C.-H. (2008). An agentbased model for consumer-to-business electronic commerce. Expert Systems with Applications, 34(2008), 469-481.

Chen, Y., \& Sudhir, K. (2004). When shopbots meet emails: implications for price competition on the internet. Quantitative Marketing and Economics, 2(3), 233-255.

Clemons, E. K. (2009). Business models for monetizing internet applications and web sites: experience, theory, and predictions. Journal of Management Information Systems, 26(2), 15-41.

Coen, M. H. (1994). "SodaBot: A software agent environment and construction system" A. I. Technical Report 1493, M. I. T. Artificial Intelligence Laboratory.

Day, G. (1999). The market driven organization: Understanding, attracting, and keeping valuable customer. New York: The Free Press.

De Figueiredo, J. M. (2000). Finding sustainable profitability in electronic commerce. Sloan Management Review, 41(4), 41-52.

Deshpande, R., Farley, J. U., \& Webster, F. E., Jr. (1993). Corporate culture, customer orientation, and innovativeness in Japanese firms: a quadrad analysis. Journal of Marketing, 57(1), 23-37.

Diehl, K., Kornish, L. J., \& Lynch, J. G., Jr. (2003). Smart agents: when lower search costs for quality information increase price sensitivity. Journal of Consumer Research, 30(1), 56-71.

Dubosson-Torbay, M., Osterwalder, A., \& Pigneur, Y. (2002). E-business model design, classification, and measurements. Thunderbird International Business Review, 44(1), 5-23.

Eisenhardt, K. M., \& Martin, J. A. (2000). Dynamic capabilities: what are they? Strategic Management Journal, 21(10-11), 1105-1121.

Fasli, M. (2007). On agent technology for e-commerce: trust, security and legal issues. The Knowledge Engineering Review, 22(1), 3-35.

Festa, P., Pardalos, P. M., \& Resende, M. G. C. (1999). Feedback Set Problems. In D.-Z. Du \& P. M. Pardalos (Eds.), Handbook of Combinatorial Optimization. Norwell: Kluwer Academic Publishers.

Franklin, S., \& Graesser, A. (1996). Is it an agent, or just a program? A taxonomy for autonomous agents. In J. Muller \& J. Gauldie (Eds.), Intelligent Agents III (pp. 21-35). Berlin: Springer.

Frazier, G. L., \& Howell, R. D. (1983). Business definition and performance. Journal of Marketing, 47(Spring), 59-67.

Frazier, G. L., Maltz, E., Antia, K. D., \& Rindfleisch, A. (2009). Distributor sharing of strategic information with suppliers. Journal of Marketing, 73(July), 31-43.

Glaser, Barney G. (1994), More Grounded Theory Methodology. A Reader, Mill Valley, Ca.: Sociology Press.

Glaser, B. G. (1998). Doing grounded theory: Issues and discussions. Mill Valley: Sociology Press.

Glaser, B. G., \& Strauss, A. L. (1967). Discovery of grounded theory: Strategies for qualitative research. Hawthorne: Aldine de Gruyter.

Glazer, R. (1991). Marketing in an information-intensive environment: strategic implications of knowledge as an asset. Journal of Marketing, 55(4), 1-19.

Goldberg, I. A. (2000). A pseudonymous communications infrastructure for the internet, doctoral dissertation, computer science. Berkeley: University of California.

Goulding, C. (2002). Grounded theory: A practical guide for management business and market researchers. London: Sage.

Greshoff, A. D., \& West, P. M. (1998). Using a community of knowledge to build intelligent agents. Marketing Letters, 9(1), 79-91.

Grewal, R., Chakravarty, A., \& Saini, A. (2010). Governance mechanisms in business-to-business electronic markets. Journal of Marketing, 74(4), 45-62.

Guttman, R. H., Moukas, A. G., \& Maes, P. (1998). Agent mediated electronic commerce: a survey. The Knowledge Engineering Review, 13(2), 147-159.

Hansen, D. R., \& Mowen, M. M. (2011). Cornerstones of cost accounting. Mason: South-Western Cengage Learning.
Hodgdon, P. N. (1997). The role of intelligent agent software in the future of direct response. Journal of Direct Marketing, 59(9), 141-143.

Hoffmann, D. L., \& Novak, T. P. (1996). Marketing in hypermedia computer-mediated environments: conceptual foundations. Journal of Marketing, 60(3), 50-68.

Huang, C.-C., Liang, W.-Y., Lai, Y.-H., \& Lin, Y.-C. (2010). The agentbased negotiating process for B2C e-commerce. Expert Systems with Applications, 37(2010), 348-359.

Huhns, M. N., \& Singh, M. P. (1998). Readings in agents. San Francisco: Morgan Kaufmann.

Hunt, S. D. (2002). Foundations of marketing theory: Toward a general theory of marketing. New York: M.E. Sharpe, Inc.

Iacobucci, D., Arabie, P., \& Bodapati, A. (2000). Recommendation agents on the internet. Journal of Interactive Marketing, 14(3), 2 11.

Iyer, G., \& Pazgal, A. (2003). Internet shopping agents: virtual colocation and competition. Marketing Science, 22(1), 85-106.

Jaworski, B. J., \& Kohli, A. K. (1993). Market orientation: antecedents and consequences. Journal of Marketing, 57(3), 53-70.

Johnson, J. L., Lee, R. P., Saini, A., \& Grohmann, B. (2003). Marketfocused strategic flexibility: conceptual advances and an integrative model. Journal of the Academy of Marketing Science, 31(1), 74-89.

Jose C. Brustoloni (1991). Autonomous Agents: Characterization and Requirements. Carnegie Mellon Technical Report CMU-CS-91204, Carnegie Mellon University

Kobsa, A., \& Schreck, J. (2003). Privacy through pseudonymity in useradaptive systems. ACM Transactions on Internet Technology, 3(2), 149-183.

Köhler, C. F., Rohm, A. J., De Ruyter, K., \& Wetzels, M. (2011). Return on interactivity: the impact of online agents on newcomer adjustment. Journal of Marketing, 75(2), 93-108.

Kohli, A. K., \& Jaworski, B. J. (1990). Market orientation: the construct, research propositions, and managerial implications. Journal of Marketing, 54(2), 1-18.

Kotler, P. (1999). Marketing Management (Millenniumth ed.). New Jersey: Prentice Hall.

Kumar, V., Jones, E., Venkatesan, R., \& Leone, R. P. (2011). Is market orientation a source of sustainable competitive advantage or simply the cost of computing? Journal of Marketing, 75(1), 16-30.

Kumar, V., \& Reinartz, W. (2012). Customer relationship management: Concept, strategy, and tools. Heidelberg: Springer.

Liang, W.-Y., \& Huang, C.-C. (2002). The agent-based collaboration information system of product development. International Journal of Information Management, 22(3), 211-224.

Liberman, H., Faabog, A., Espinosa, J. M., \& Stocky, T. (2004). Commonsense on the go. BT Technology Journal, 22(4), 241-252.

Liu, H, Lieberman, H and Selker, T (2002). "Automatic affective feedback in an email browser," in MIT Media Laboratory Software Agent Group Technical Report, November.

Lynch, J. G., Jr., \& Ariely, D. (2000). Wine online: search cost affect competition on price. quality, and distribution. Marketing Science, 19(1), 83-101.

MacKenzie, S. B., \& Lutz, R. J. (1989). An empirical examination of the structural antecedents of attitude toward the ad in an advertising pretesting context. Journal of Marketing, 53(2), 48-65.

Maes, P. (1994). Agents that reduce work and information overload. Communications of the ACM, 37(7), 30-40.

McAfee, A., \& Brynjolfsson, E. (2008). Investing in the it that makes a competitive difference. Harvard Business Review, 86(7/8), 98-107.

Menguc, B., \& Auh, S. (2006). Creating a firm-level dynamic capability through capitalizing on market orientation and innovativeness. Journal of the Academy of Marketing Science, 34(1), 63-73.

Montgomery, A. L., Hosanagar, K., Krishnan, R., \& Clay, K. B. (2004). Designing a better shopbot. Management Science, 50(2), 189-206. 
Moorman, C., Deshpandé, R., \& Zaltman, G. (1993). Factors affecting trust in market research relationships. Journal of Marketing, 57(1), 81-101.

Morgan, G. (1997). Images of organizations (2nd ed.). California: Sage Pubs, Inc.

Murthi, B. P. S., \& Sarkar, S. (2003). The role of the management science in research on personalization. Management Science, 49(10), 13441362.

Narver, J. C., \& Slater, S. F. (1990). The effect of a market orientation on business profitability. Journal of Marketing, 54(4), 20-35.

Němacová, Z., \& Dvořák, J. (2011). The model of e-commerce strategy focused on customers. Economics and Management, 16, 1292 1297.

Olson, E. M., Slater, S. F., \& Hult, G. T. M. (2005). The importance of structure and process to strategy implementation. Business Horizon, $48,47-54$.

Osterwalder, A (2009). "Business model alchemist: Scanning your business model's environment" (accessed April 25, 2011), [available at http://www.businessmodelalchemist.com/2009/07/scanning-yourbusiness-models.html].

Palmatier, R. W., Dant, R. P., \& Grewal, D. (2007). A comparative longitudinal analysis of theoretical perspectives of interorganizational relationship performance. Journal of Marketing, 71(4), 172-194.

Pant, G., \& Menczer, F. (2002). Myspiders: evolve your own intelligent web crawlers. Autonomous Agents and Multi-Agent Systems, 5(2), 221-229.

Peppers, D., Rogers, M., \& Dorf, B. (1999). Is your company ready for one-to-one marketing? Harvard Business Review, 77(1), 151-160.

Maes, P. ed (1991). Designing autonomous agents, MIT Press.

Porter, M. E. (2001). Strategy and the internet. Harvard Business Review, 79(3), 62-78

Preist, C, Bartolini, C and Phillips, I (2001). "Algorithm design for agents which participate in multiple simultaneous auctions" AgentMediated Electronic Commerce III: Lecture Notes in Computer Science, $139-54$.

Hayes-Roth, R (1995). An architecture for adaptive intelligent systems. Artificial Intelligence: Special Issue on Agents and Interactivity, (72): 329-365

Reibstein, D. J. (2002). What attracts customers to online stores, and what keeps them coming back? Journal of the Academy of Marketing Science, 30(4), 465-473.

Rogers, E. M. (1995). Diffusion of innovations (4th ed.). New York: Free Press.

Russell, S. J. and P. Norvig (1995). Artificial intelligence: A modern approach. Prentice Hall.

Rust, R. T., Lemon, K. N., \& Zeithaml, V. A. (2004). Return on marketing: using customer equity to focus marketing strategy. Journal of Marketing, 68(1), 109-127.

Rust, R. T., \& Oliver, R. W. (1994). The death of advertising. Journal of Advertising, 23(4), 71-77.

Rust, R. T., \& Varki, S. (1996). Rising from the ashes of advertising. Journal of Business Research, 37(3), 173-181.

Schurr, P. H., \& Ozanne, J. L. (1985). Influence on exchange processes: buyers' preconceptions of a seller's trustworthiness and bargaining toughness. Journal of Consumer Research, 11(4), 939-953.

Senge, P. M. (1990). The fifth discipline: The art and practice of the learning organization. NewYork: Doubleday/Currency.

Shardanand, U and Maes, P (1995), "Social information filtering: algorithms for automating 'word of mouth'," in Proceedings of CHI'95, Human Factors in Computing Systems, 210-17.

Sheng, Y. P., Mykytyn, P. P., Jr., \& Litecky, C. R. (2005). Competitor analysis and its defenses in the e-marketplace. Communications of the ACM, 48(8), 107-112.

Sinkovics, R. R., Penz, E., \& Ghauri, P. N. (2005). Analyzing textual data in international marketing research. Qualitative Marketing Research: An International Journal, 8(1), 9-38.
Smith, M. D. (2002). The impact of shopbots on electronic markets. Journal of the Academy of Marketing Science, 30(4), 446-454.

Smith, M. D., \& Brynjolfson, E. (2001). Customer decision making at an internet shopbot: brand matters. Journal of Industrial Economics, 49(4), 541-558.

Smith, D. C., Cypher, A., \& Spohrer, J. (1994). Kidsim: programming agents without a programming language. Communications of the $A C M, 7(37), 55-67$.

Somefun K, Gerding, E, Bohte,S and La Poutré, H. (2003). “Automated negotiation and bundling of information goods" in Proceedings of the 5th Workshop on Agent Mediated Electronic Commerce (AMEC V). Melbourne, Australia.

Stewart, D. W., \& Pavlou, P. A. (2002). From consumer response to active consumer: measuring the effectiveness of interactive media. Journal of the Academy of Marketing Science, 30(4), 376-396.

Strauss, A. L., \& Corbin, J. M. (1998). Basics of qualitative research: Techniques and procedures for developing grounded theory (2nd ed.). Thousand Oaks: Sage.

Sujan, H., Weitz, B. A., \& Kumar, N. (1994). Learning orientation, working smart, and effective selling. Journal of Marketing, 58(3), 39-52.

Tanimoto, J., \& Fujii, H. (2003). A study of diffusional characteristics of information on a human network analyzed by a multi-agent simulator. The Social Science Journal, 40(3), 479-485.

Taylor, J. W. (1992). Competitive intelligence: a status report on US business practices. Journal of Marketing Management, 8, 117-125.

Teece, D. J., Pisano, G., \& Shuen, A. (1997). Dynamic capabilities and strategic management. Strategic Management Journal, 18(7), 509533.

Tellis, G. J. (1986). Beyond the many faces of price: an integration of pricing strategies. Journal of Marketing, 50(4), 146-160.

Timmers, P and Gasós, J (2001)."Agent technologies and business models for electronic commerce" In Agent-Mediated Electronic Commerce III, Current Issues in Agent Based Electronic Commerce Systems, Springer, 177-90.

Titkov, L., Poslad, S., \& Tan, J. J. (2006). An integrated approach to user centered privacy for mobile information services. Applied Artificial Intelligence, 20(2-4), 159-178.

Urban, G. L., Sultan, F., \& Qualls, W. (1999). Design and evaluation of a trust based advisor on the internet. Cambridge: Sloan School of Management, Massachusetts Institute of Technology.

Varadarajan, P. R., \& Yadav, M. S. (2002). Marketing strategy and the internet: an organizing framework. Journal of the Academy of Marketing Science, 30(4), 296-312.

Vulkan, N., \& Jennings, N. R. (2000). Efficient mechanisms for the supply of services in multi-agent environments. Decision Support Systems, 28(1-2), 5-19.

Warkentin, M, Sugumaran, V and Bapna, R (2001)."Intelligent agents for electronic commerce: trends and future impact on business models and markets." in Agent-Mediated Electronic Commerce III, Current Issues in Agent Based Electronic Commerce Systems, Springer, 101-20.

Wiedmann, K. P., Walsh, G., \& Mitchell, V. W. (2001). The mannmaven: an agent for diffusing market information. Journal of Marketing Communications, 7(4), 195-212.

Wooldridge, M. (2002). An introduction to multi agent systems. Chichester: John Wiley and Sons.

Zahay, D. L., \& Handfield, R. B. (2004). The role of learning and technical capabilities in predicting adoption of B2B technologies. Industrial Marketing Management, 33, 627-641.

Zhao, K., Xia, M., \& Shaw, M. J. (2007). An integrated model of consortium bases e-business standardization: collaborative development and adoption with network externalities. Journal of Management Information Systems, 23(4), 247-271.

Zhu, Z., Nakata, C., Sivakumar, K., \& Grewal, D. (2007). Self-service technology effectiveness: the role of design features and individual traits. Journal of the Academy of Marketing Science, 35(4), 492-506. 